\title{
Albendazole treatment of pulmonary hydatid cysts in naturally infected sheep: a study with relevance to the treatment of hydatid cysts in man
}

\author{
DL MORRIS, MJ CLARKSON, MF STALLBAUMER, J PRITCHARD, RS JONES, \\ JB CHINNERY
}

From the Department of Surgery, University Hospital, Nottingham; the Department of Veterinary Clinical Science, Division of Farm Animal Medicine, Veterinary Field Station, University of Liverpool; and the Department of Anaesthesia, Royal Liverpool Hospital, Liverpool

ABSTRACT Albendazole was given orally to sheep with naturally occurring live pulmonary and hepatic cysts. The viability of pulmonary cysts was established before treatment by thoracotomy and needle puncture. Both 10 and $20 \mathrm{mg} / \mathrm{kg} /$ day doses were found effective in that no viable protoscoleces were found after six weeks' treatment in either group while untreated controls still had viable cysts. In addition, treated animals showed macroscopic and electron microscopic changes. Bone marrow toxicity probably occurred in two sheep.

Hydatid disease in man is caused by infection with Echinococcus granulosus or $E$ multilocularis and usually presents with symptoms from hepatic or pulmonary cysts. It is a widespread problem throughout the world and until recently the only effective treatment was surgical excision. ${ }^{1}$ Mebendazole was the first drug shown to be of benefit in animals, ${ }^{23}$ and early clinical results were encouraging. ${ }^{4}$ Other patients have failed to benefit despite prolonged high dose treatment. ${ }^{5}$ Mebendazole is an extremely insoluble and therefore poorly absorbed drug $^{6}$ and the variable clinical results may correlate with blood concentrations. ' Concentrations of the metabolites of mebendazole (methyl 5-(hydroxybenzyl)-2-benzimidazole carbamate and 2-amino-5-benzimidazole) are higher, ${ }^{8}$ but these metabolites are not thought to have potent anthelmintic activity ( $\mathrm{H}$ Vanden Bosche, personal communication).

Albendazole (Smith, Kline, and French) is partly absorbed (less than $0.4 \%$ of a $400 \mathrm{mg}$ oral dose) and is rapidly converted into three principal metabolites: sulphoxide, sulphone, and 2-aminosulphone, the first of which is probably responsible for the anthelmintic activity of the drug." Maximum serum con-

Address for reprint requests: Mr DL Morris FRCS, West Block (Floor E), University Hospital, Nottingham NG7 2UH.

Accepted 29 January 1985 centrations of about $0.3 \mu \mathrm{g} / \mathrm{ml}$ albendazole sulphoxide may be expected in sheep one to three hours after a single oral dose of $10 \mathrm{mg} / \mathrm{kg}$."

The relative efficacy of these metabolites or those of mebendazole for the treatment of human hydatid disease are not yet known.

Early clinical ${ }^{1011}$ and radiographic ${ }^{12}$ results with albendazole in human hydatid disease are promising. Initial results with mebendazole were, however, encouraging and even computed tomographic evidence of cyst regression after albendazole treatment does not constitute absolute proof of therapeutic action, because spontaneous regression of hydatid disease does occasionally occur. ${ }^{13}$ Similarly, it is not possible in man to be sure that a given cyst is viable before treatment, as needle aspiration is contraindicated because of the hazard of anaphylaxis and the risk of dissemination due to implantation of spilled protoscoleces.

The use of rodent models with peritoneal hydatid disease is probably of little relevance to the treatment of hepatic and pulmonary cysts in man because the peritoneal cysts have extremely thin walls with virtually no ectocyst layer. We have used sheep with naturally occurring hydatid cysts as a model to assess the value of albendazole in the treatment of hydatid disease in man. The model is similar to that of Gemmell et $\mathrm{l}^{3}$ but has been improved in that sheep were selected by radiography and in addition, in the second phase of the study, by confirming viability of 

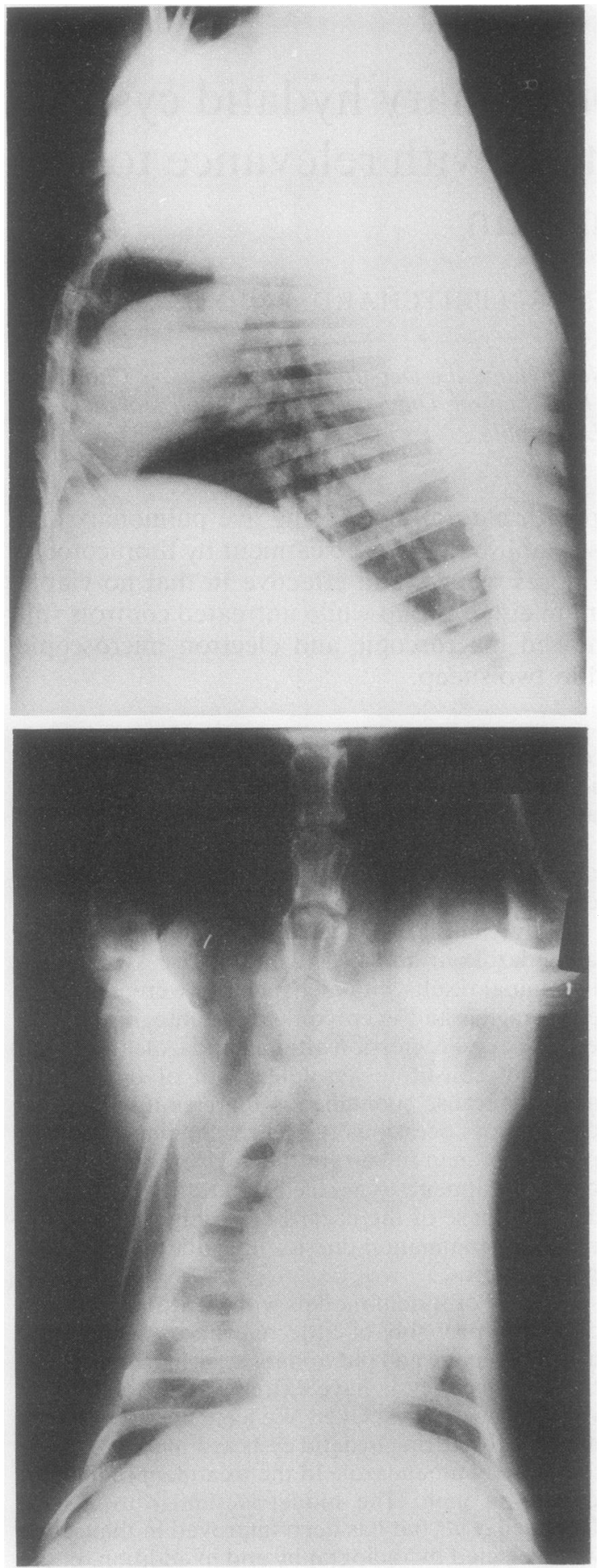

Fig 1 Chest radiograph of a sheep with a pulmonary cyst. the cysts by needle puncture at thoracotomy before the start of drug treatment.

\section{Methods}

Welsh Cross ewes were purchased from two farms in mid Wales where the dogs had been shown to be infected with $E$ granulosus. The ewes were culled because they were very thin owing to tooth disease and loss. They had lived on the farms for at least six years.

The sheep had chest radiography and those with large uncalcified cysts (which previous experience had indicated were likely to be viable) were selected, according to a previously described technique..$^{14}$

In the first phase, four sheep were treated with oral albendazole (SK and F, Valbazen) at $20 \mathrm{mg} / \mathrm{kg}$ / day for five days of each week in a single oral dosage. Treatment was continued for six weeks, and necropsy was performed at death or on completion of treatment. The cysts were examined and were then aspirated to obtain protoscoleces, which were observed under a microscope immediately for flame cell activity and then tested for their ability to exclude $5 \%$ aqueous eosin. ${ }^{15}$

In the second phase of the study, 10 sheep with radiographic evidence of large pulmonary cysts underwent thoracotomy. Anaesthesia was induced with pentobarbitone sodium and maintained with nitrous oxide/oxygen and halothone, an East Radcliffe ventilator being used. The cysts were aspirated with a $21 \mathrm{G}$ needle and 1-2 $\mathrm{ml}$ of fluid removed; this was reinjected and withdrawn or the cyst shaken to suspend any protoscoleces contained in the cyst. These protoscoleces were then examined for viability. If aspiration of the first cyst confirmed viability no further cysts were punctured, but if the first cyst was not viable further cysts were examined. The use of intercostal tube drains was judged impractical, but the size of any pneumothorax was minimised by fully inflating the lungs during the final parts of the chest closure. In two sheep no viable protoscoleces were found and they were excluded from the study. Of the remaining eight sheep, six were treated at 10 $\mathrm{mg} / \mathrm{kg} /$ day for six weeks and two sheep remained untreated. All sheep underwent necropsy at death or at the completion of treatment.

In addition to the viability tests described for phase 1 , segments of germinal membrane were examined by electron microscopy. During treatment? haemoglobin, total and differential white cell $T$ counts, and serum sorbitol dehydrogenase activity were measured weekly in phase 2 of the study. Finally, a further four sheep with live cysts remained as untreated controls for six weeks after thoracotomy and then underwent necropsy. 
Cyst numbers and sites in phase 2 of the study

\begin{tabular}{|c|c|c|c|c|}
\hline $\begin{array}{l}\text { Sheep } \\
\text { No }\end{array}$ & \multicolumn{2}{|c|}{ Site and No of cysts } & Treatment & Necropsy \\
\hline $\begin{array}{l}329 \\
322 \\
210 \\
298 \\
219 \\
230\end{array}$ & \multicolumn{2}{|l|}{$\begin{array}{l}\text { Lung } 2 \\
\text { Lung } 9 \\
\text { Lung } 5 \\
\text { Lung } 2 \\
\text { Lung } 10 \\
\text { Lung } 3\end{array}$} & Alb $10 \mathrm{mg} / \mathrm{kg}$ per day & $\begin{array}{l}\text { Little fluid, infected } \\
\text { Flaccid, separation of laminated } \\
\text { membrane, cloudy fluid; no viable } \\
\text { protoscoleces }\end{array}$ \\
\hline 222 & $\begin{array}{l}\text { Lung } 7 \\
\text { Lung } 1\end{array}$ & Liver 6 & Nil & $\begin{array}{l}\text { Tense, clear fluid; viable } \\
\text { protoscoleces }\end{array}$ \\
\hline $\left.\begin{array}{l}295 \\
327\end{array}\right\}$ & \multicolumn{4}{|c|}{ Cysts not viable-excluded from study } \\
\hline
\end{tabular}

Alb-albendazole.

\section{Results}

PHASE 1

The macroscopic appearance of cysts in the treated sheep at necropsy differed from their usual appearance in that they were flaccid and contained little fluid. Instead of the crystal clear fluid seen in viable cysts the fluid was yellowish and clotted when allowed to stand, suggesting an increase in protein content. All protoscoleces in the treated sheep appeared dead (there was no motility or flame cell activity and all stained with aqueous esoin). One sheep treated with albendazole in a dose of $20 \mathrm{mg} /$ $\mathrm{kg}$ /day died after four weeks' treatment of pasteurella septicaemia. Cysts visible on chest radiographs are shown in figure 1.

\section{PHASE 2}

The sheep tolerated thoracotomy well despite their age and poor condition. The results are summarised in the table. One of the treated sheep (No 322) died after five and a half weeks of treatment with acute pneumonia, but no organisms were grown from the lungs or blood. Considerable reductions in total white cell count and polymorph count were seen in this sheep (fig 2), but there was no such effect in the remaining five animals. There were no significant differences in the serum sorbitol dehydrogenase activity of the treated and untreated sheep, this enzyme being a good measure of hepatic cell damage in sheep. In the treated sheep many protoscoleces were present but no viable protoscoleces were seen, all being shrunken, immotile, and staining with eosin. Gerbil intraperitoneal injections of protoscoleces from the treated sheep failed to show any evidence of viability. Cysts that had been punctured earlier did not differ in appearance from those that had not been punctured, except for the pleural adhesions to the former that were frequently found. Hepatic cysts were also flaccid and contained yellow fluid and dead protoscoleces. Several cysts of 5-10 $\mathrm{cm}$ in diameter were seen and all appeared dead.

The control sheep, which had thoracotomy and confirmation of the viability of cysts but received no albendazole, still had viable protoscoleces within tense cysts containing clear fluid at necropsy,

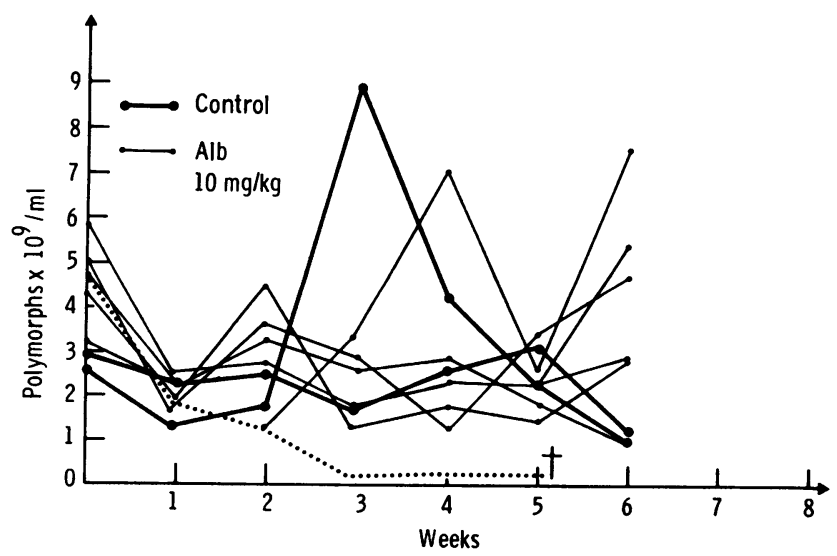

Fig 2 Polymorph count during albendazole (alb) treatment in phase 2. The heavy lines indicate results for two control animals and the broken line for the treated sheep that died. 

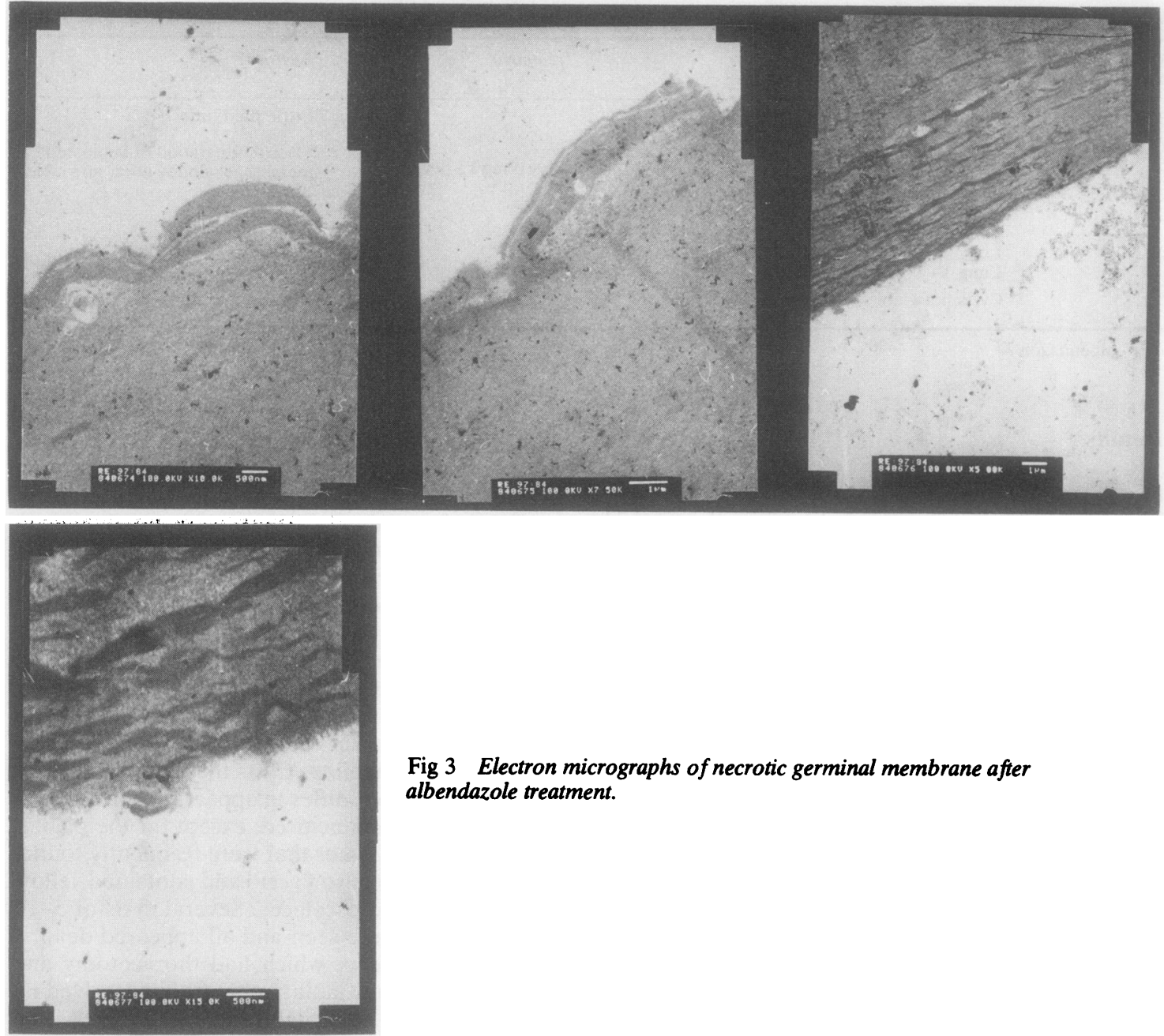

Fig 3 Electron micrographs of necrotic germinal membrane after albendazole treatment.

whether the cyst had been punctured previously or not. Electron microscopy of the germinal membranes and laminated membrane showed severe degeneration affecting all areas of the germinal membrane in the treated sheep (fig 3) but intact membranes in the controls (fig 4).

The last four control sheep were found to have multiple viable pulmonary and hepatic cysts at necropsy.

\section{Discussion}

The chemotherapy of human hydatid disease could be of great importance in patients with inoperable cysts or multiple cysts and in those unfit for surgery or perhaps suffering from recurrent disease, where operative mortality is higher. ${ }^{16}$ Similarly, effective chemotherapy would be a major breakthrough in the treatment of $E$ multilocularis, which is almost invariably fatal ${ }^{17}$; and albendazole would be worth a trial. While patients with cysts due to $E$ granulosus who have been treated with albendazole have shown both clinical and radiographic evidence of response, neither type of response is direct evidence of efficacy, for cysts may have already been dead or have been in the process of spontaneous disappearance. ${ }^{13}$

We have used adult sheep with naturally occurring pulmonary and hepatic hydatid disease as this closely simulates the disease seen in man. In particular, a rodent peritoneal cyst model would seem very different from the cysts seen in man. Our results are extremely encouraging in that no viable proto- 


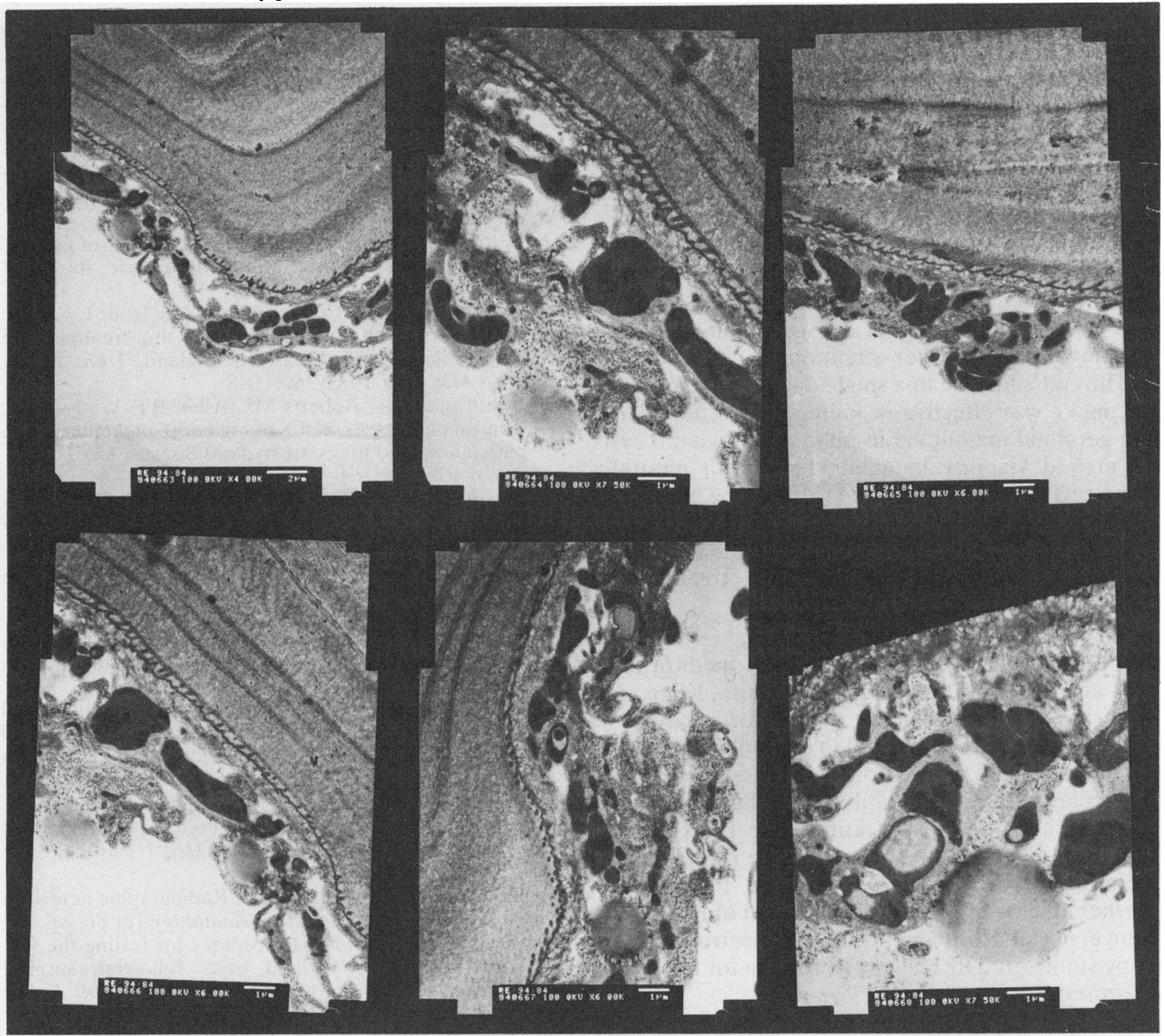

Fig 4 Electron micrographs of germinal membrane from an untreated control sheep showing viable membrane.

scoleces were seen in any of the treated animals, the cysts appeared flaccid, and the laminated and germinal membrane had separated from the host ectocyst. This separation was noted on computed tomography and ultrasound scanning in some patients having albendazole treatment. ${ }^{12}$ The degenerate remnants of the germinal membranes seen by electron microscopy support the data on viability and macroscopic appearance and are similar to those seen with mebendazole in a rodent peritoneal model..$^{18}$

Bone marrow depression probably played a contributory part in the death of two treated ewes; but no such problem has been encountered in man. This may be related to two factors other than interspecies variation. The albendazole was given to the sheep in a single daily dose, thus producing much higher peak concentrations, which would be accentuated by the increased absorption that occurs in sheep. Mean peak serum concentrations of albendazole sulphoxide and sulphone in sheep after a single daily dose of $10 \mathrm{mg} / \mathrm{kg}$ of albendazole are of the order of 3.2 and $0.9 \mu \mathrm{g} / \mathrm{ml}$ respectively, which is several times higher than those achieved in man. ${ }^{1}$ Neutropenia has been reported during mebendazole treatment of hydatid disease in man, ${ }^{14}$ but our experience of bone marrow depression in animals with albendazole has not yet been reflected in man. This difference in dosage and 
pharmacokinetics must also be considered when taking into account the apparently excellent efficacy of albendazole in this model at doses of both 10 and 20 $\mathrm{mg} / \mathrm{kg} /$ day. Possibly the lower peak concentrations, due to poorer absorbtion, and the divided dosage used in man will not be as effective as in sheep, which appears to be true of mebendazole treatment, where there are good data on the efficacy of the drug in a similar sheep model; but this drug has been less effective in clinical practice. We considered it important, however, first to decide whether albendazole was effective; the optimal dosage required in man can now receive further attention.

Thus albendazole in a single daily dosage of 10 or $20 \mathrm{mg} / \mathrm{kg}$ was effective in killing protoscoleces and the germinal membrane in pulmonary hydatid cysts of proved viability in adult sheep with naturally occurring disease. These data support the belief that albendazole may exert a therapeutic action in hydatid disease in man, but careful monitoring of the white cell count during human treatment is advised.

We are most grateful to the overseas medical division and the veterinary division of Smith, Kline, and French for financial support and for supplies of albendazole. We are grateful to our colleagues at the Veterinary Field Station for their generous help and particularly for radiographic and haematological examinations. We also acknowledge the care and attention given to the sheep by Helen Michell and Janette Perry. We are grateful to Professor D Turner and Mr S Terrace, Department of Pathology, University of Nottingham, for the electron microscopy studies and to Theresa Borowska for typing the manuscript.

\section{References}

1 Morris DL. The management of hydatid disease. British Journal of Hospital Medicine 1980;24:586-95.

2 Heath DD, Chevis RAF. Mebendazole and hydatid cysts. Lancet 1974 ;ii: 218-9.

3 Gemmel MA, Parmeta SN, Sutton RJ, Khan N. Effect of Mebendazole against Echinococcus granulosus and Taenia hydatigena cysts in naturally infected sheep and relevance to larval tapeworm infections in man. $Z$ Parasitenkd 1981;64:135-47.

4 Bekhti A, Schaaps UP, Capron M, Dessaint JP, Santoro F, Capron A. Treatment of hepatic hydatid disease with mebendazole: preliminary results in four cases. $\mathrm{Br}$ Med J 1977; ii: 1047-51.

5 Braithwaite PA. Long term high dose mebendazole for cystic hydatid disease of the liver: failure in two cases. Aust N Z J Surg 1981;51:23-7.

6 Morris DL, Gould S. Serum and Cyst levels of mebendazole and flubendazole in hydatid disease. $\mathrm{Br}$ Med J 1982;285: 175 .

7 Bryceson ADM, Cowie AGA, Macleod C, et al. Experience with mebendazole in the treatment of inoperable hydatid disease in England. Trans $R$ Soc Trop Med Hyg 1982;76:510-8.

8 Braithwaite PA, Roberts MS, Allen RT, Watson TR. Clinical pharmacokinetics of high dose mebendazole in patients treated for cystic hydatid disease. Eur J Pharmacol 1982;22: 161-9.

9 Marriner SE, Bogan JA. Pharmacokinetics of albendazole in sheep. American Journal of Veterinary Research 1980;41:1126-9.

10 Morris DL, Dykes PW, Dickson B, Marriner SE, Bogan J, Burrows FGO. Albendazole in hydatid disease. $\mathrm{Br}$ Med J 1983; 280: 103-4.

11 Saimot AG, Meulemans A, Cremieux AC, et al. Albendazole as a potential treatment for human hydatidosis. Lancet 1983;ii:652-6.

12 Morris DL, Skeene Smith H, Burrows F. Abdominal hydatid disease: computed tomographic and ultrasound changes during albendazole therapy. Clin Radiol 1984;35:297-300.

13 Zhongxi Q, Shuyuan G, Guozne T, et al. Immediate and long term results of surgical treatment of intrathoracic hydatic cysts. Chin Med J 1980;93:56972.

14 Wyn Jones CR, Clarkson MJ. Radiographic detection of ovine hydatid. Veterinary Radiology (in press).

15 Smyth JD, Barrett NJ. Procedures for testing the viability of human hydatid cysts following surgical removal especially after chemotherapy. Trans $R$ Soc Trop Med Hyg 1980; 74:849-52.

16 Amir Jahed AK, Fardin R, Farzad A, Bakshandeh K. Clinical echinococcosis. Ann Surg 1975; 182: 541-6.

17 Mossiman JF. Is alveolar hydatid disease of the liver incurable? Ann Surg 1980;192: 118-23.

18 Verheyen A. Echinococcus granulosus. The influence of mebendazole therapy on the ultrastrictural morphology of the germinal layer of hydatid cysts in humans and mice. $Z$ Parasitenkd 1982;67:55-65.

19 Levin MH, Weinstein RA, Axelrod JL, Schantz PM. Neutropenia and Mebendazole. JAMA 1983;249: 2929-31. 